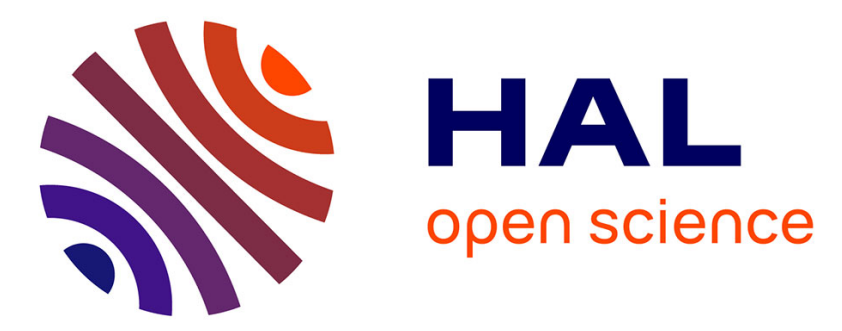

\title{
Application of photothermal probe beam deflection technique for ablation and damage measurements by using short UV - laser pulses
}

E. Welsch, K. Ettrich, M. Peters, W. Ziegler, H. Blaschke

\section{To cite this version:}

E. Welsch, K. Ettrich, M. Peters, W. Ziegler, H. Blaschke. Application of photothermal probe beam deflection technique for ablation and damage measurements by using short UV - laser pulses. Journal de Physique IV Proceedings, 1994, 04 (C7), pp.C7-749-C7-752. 10.1051/jp4:19947176 jpa-00253237

HAL Id: jpa-00253237

https://hal.science/jpa-00253237

Submitted on 1 Jan 1994

HAL is a multi-disciplinary open access archive for the deposit and dissemination of scientific research documents, whether they are published or not. The documents may come from teaching and research institutions in France or abroad, or from public or private research centers.
L'archive ouverte pluridisciplinaire HAL, est destinée au dépôt et à la diffusion de documents scientifiques de niveau recherche, publiés ou non, émanant des établissements d'enseignement et de recherche français ou étrangers, des laboratoires publics ou privés. 


\title{
Application of photothermal probe beam deflection technique for ablation and damage measurements by using short UV - laser pulses
}

E. Welsch, K. Ettrich, M. Peters, W. Ziegler and H. Blaschke

Friedrich-Schiller-Universität, Institut für Optik und Quantenelektronik, Max-Wien-Platz I,

07743 Jena, Germany

\begin{abstract}
For application in UV-material processing and UV-thin-film optics, the thermal contribution to damage and ablation phenomena will be investigated utilizing time resolved photothermal probe beam deflection (MIRAGE) technique.

The potentiality of this method for the determination of both the sub-damage range and the Onset of damage, as well as the ablation threshold by using the thermal branch of MIRAGE technique will be demonstrated.
\end{abstract}

\section{INTRODUC'TION}

Ablation phenomena can be advantageously analyzed utilizing photothermal detection $[1,2]$. Despite the fact that UV laser interaction with sample surfaces is often governed by photochemical processes $[3,4]$, the material response will be accompanied by thermal as well as acoustic contribution and, in turn, is detectable at least partially by photothermal, respective photoacoustic technique $[5,6]$.

The investigation of the physical origin of phenomena such as laser-induced ablation, damage resistivity, and incubation as well as accumulation effects in different materials may be of basic interest in the field of thin film optics, micromachining, material processing and medical applications. Selected experimental results at organic substrates, metals, ceramics and optical thin films will be presented by using both the pulsed thermal and acoustic MIRAGE-technique. A high value is set on the careful separation of the shock-wave and thermal induced branch of the related material response from each other. 


\section{EXPERIMENTAL}

In order to determine the thermal as well as acoustic contribution in pulsed laser induced ablation and damage phenomena, the sample surface temperature response the accompanied acoustic shock wave induced change of the refractive index above the surface can be suitable measured by using MIRAGE technique. The deflection angle $\delta_{\varepsilon}$ of the probe beam direction is given by

$$
\delta \varepsilon \sim \frac{\partial n}{\partial T} \frac{\partial T}{\partial z} d z+\frac{\partial n}{\partial p} \frac{\partial p}{\partial z} d z
$$

where the terms are responsible for the thermal (left) and the shock-wave branch (right), respectively, which are operating in distinct time regimes. Pulsed MIRAGE measurements are well established methods for surface and thin-film material characterization. The sample surface irradiated by a $20 \mathrm{nsec}, 248 \mathrm{~nm} \mathrm{KrF}$ excimer laser, in principle, will be scanned two dimensionally by a completely automated system. We used an experimental set up similar to that commonly used and described in detail elsewhere $[1,7]$. The measured signal has been taken as a average over defined lateral linear scans at the sample surface, hence performing single-shot technique.

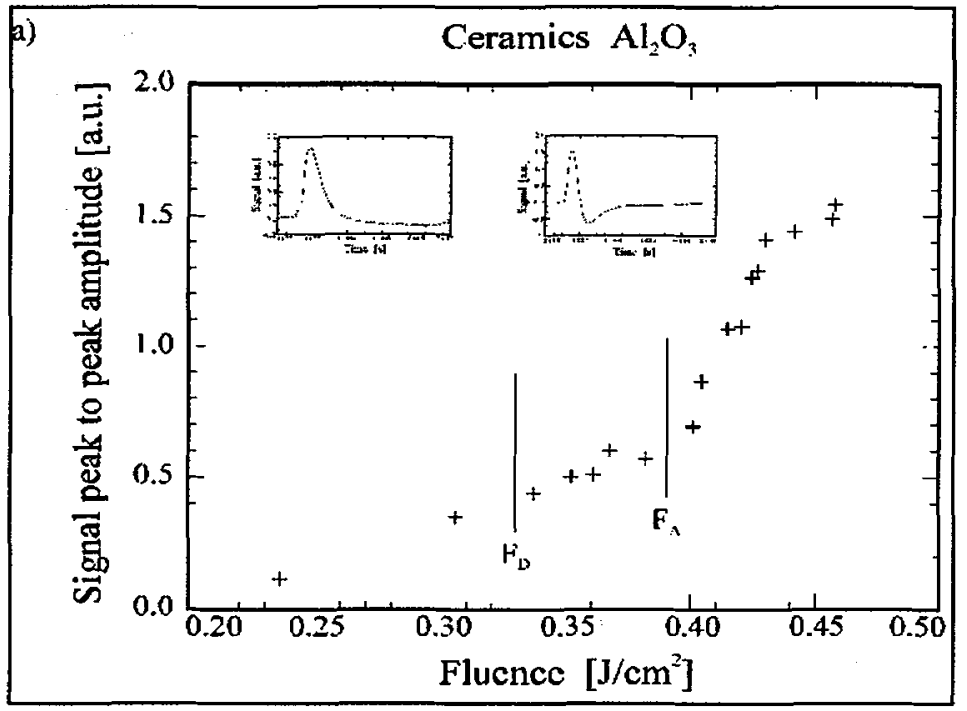

Fig.1: Typical fluence dependencies of the thermal MIRAGE probe beam deflection amplitude for sintered $\mathrm{Al}_{2} \mathrm{O}_{3}$ ceramics. Each data point was recorded at a virgin surface spot (1-on-1 technique). Windows above: The related signal versus time immediately below and above the vertical break $\left(F_{D}\right)$.

\section{RESULTS AND DISCUSSION}

Some typical materials in this field such as metals, polymers, $\mathrm{Al}_{2} \mathrm{O}_{3}$ ceramics and optical thin films have been selected for measurements. We chose UV-HR coatings consisting of 41 alternating layers of $\mathrm{Al}_{2} \mathrm{O}_{3}$ and $\mathrm{SiO}_{2}$ with an optical thickness of $\lambda / 4$ on $\mathrm{SQ} 1$ quartz substrate. 
In this paper we report on results from sintered ceramics and optical HR coatings as representative results of our investigation.

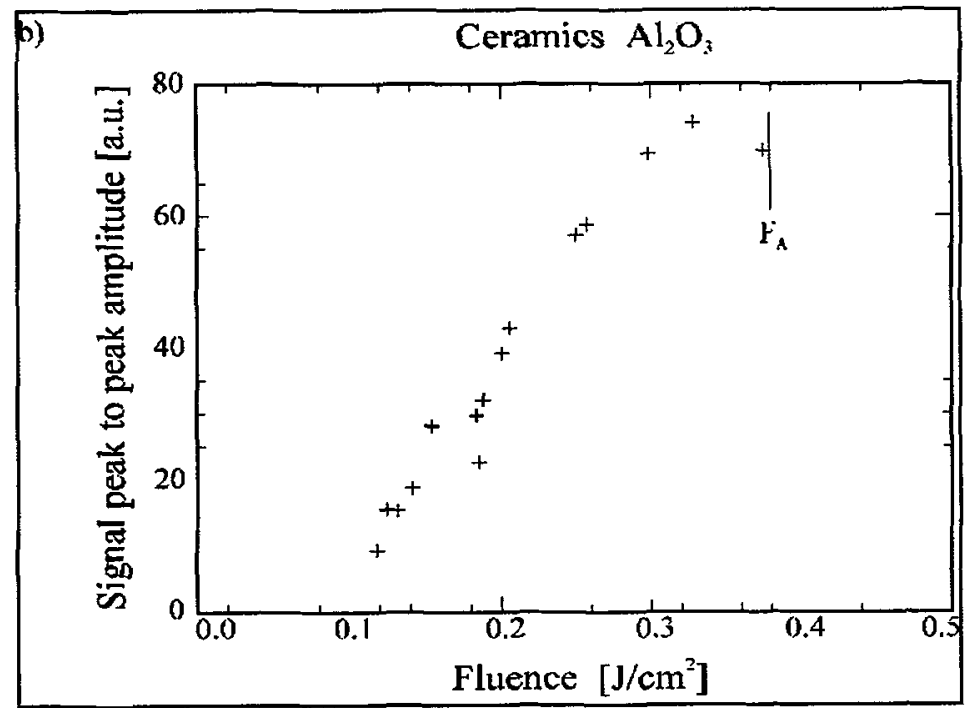

Fig.2: Typical fluence dependencies of the acoustic MIRAGE amplitude for the same sintered $\mathrm{Al}_{2} \mathrm{O}_{3}$ ceramics sample including the ablation threshold $\mathrm{F}_{\mathrm{A}}$.

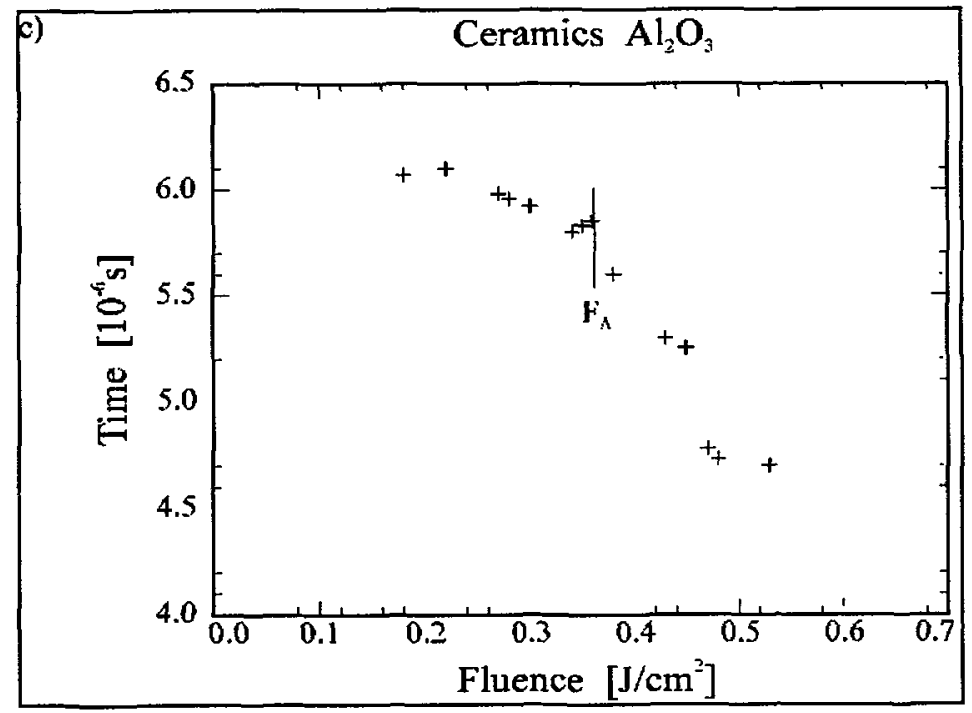

Fig.3: Transit time of the pressure wave between surface and probe beam as a function of fluence for the sample as presented in Figs. 1 and 2

Figs. 1 - 3 show the thermal, acoustic (i.e. shock wave) response, and the measured transit time of the pressure wave between target surface and probe beam as a function of fluence, respectively for a sintered ceramics. According the theoretical calculations [1] the changing from the signal governed by heat diffusion to the signal which is merely caused by surface melting and governed by airconvection and movement of ablation products, see Fig.1, marks the begin of the irreversible range of the investigated sample surface. Note that this data point $F_{D}$ cannot be found by acoustic detection. 
The second finding is the fluence of ablation threshold $\left(\mathrm{F}_{\mathrm{A}}\right)$. This ablation threshold can be determined independently by the thermal and shockwave detection (see Fig.2), as well as by measuring the transit time [8] (see Fig.3) and signals the onset of evaporation.

In Fig. 4 there is presented the thermal MIRAGE response of the $\mathrm{Al}_{2} \mathrm{O}_{3} / \mathrm{SiO}_{2}-\mathrm{HR}$ coating. The onset point of the irreversible thin film changing is clearly detectable. Furthermore, it should be emphasized that, similar to the linear increase of the signal in ceramics below the damage threshold, the material response in the HR-coating has been also measured. Thus, thermal MIRAGE technique can be considered as a alternative and very sensitive experimental technique for onset determination of functional optical breakdown in thin-films.

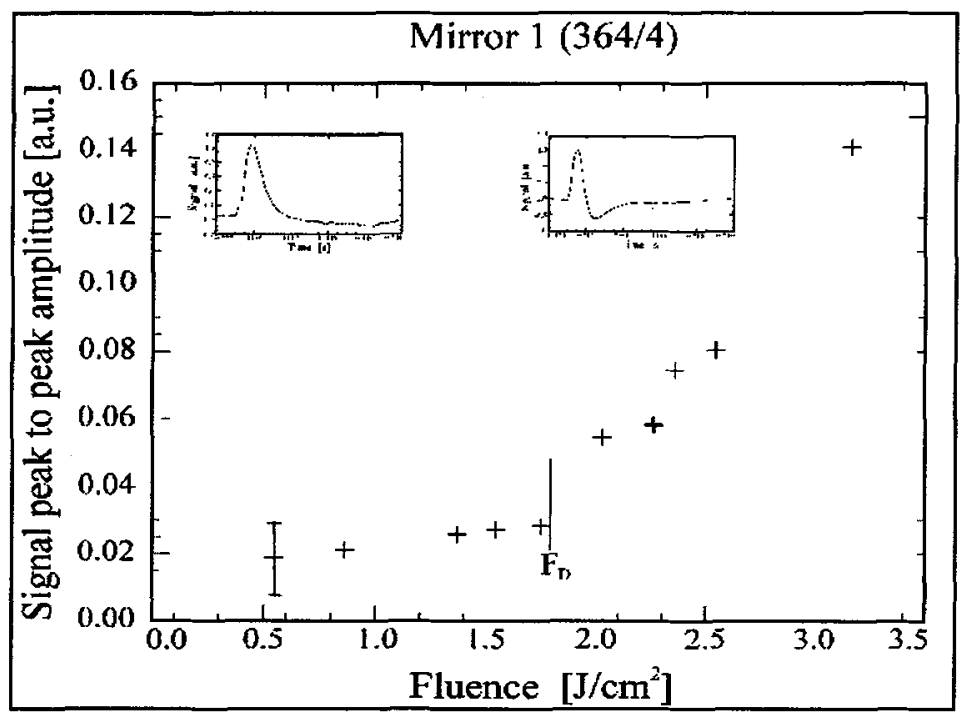

Fig.4: Typical fluence dependencies of the thermal MIRAGE amplitude for the $\mathrm{Al}_{2} \mathrm{O}_{3} / \mathrm{SiO}_{2}$-HR coating (1-on-19. Windows above: The related signal immediately below and above the Damage Fluence $F_{D}$.

\section{ACKNOWLEDGEMENTS}

The authors would like to express and their sincere appreciation for the financial support by the Alexander-von-Humboldt-Foundation and for stimulating discussions and continued support by E.Matthias, M.Reichling, N.Kaiser, H.Uhlig and A.Bodemann.

\section{REFERENCES}

[1] J.A.Sell, D.M.Heffelfinger, P.L.G.Ventzek and R.M.Gilgenbach: Photoacoustic and photothermal beam deflection as a probe of laser ablation of materials. J.Appl.Phys., 69(3):1330-1336, 1991

[2] E.Matthias et al.: Photoacoustic and photothermal investigations of thin films. Springer Ser.Opt.Sc.Vol.69, 1992

[3] G.H.Pettit, R.Sauerbrey: Pulsed UV laser ablation. Appl.Phys.A, 56:51-63, 1993

[4] R.Srinivasan, B.Braren, R.W.Dreyfus: UV laser ablation of polymide films. J.Appl.Phys., 61(1):372, 1987

[5] G.Gorodetsky, T.G.Kazayaka, R.L.Melcher and R.Srinivasan: Calorimetric and acoustic study of ultraviolet laser ablation of polymers. Appl.Phys.Lett.,46(9):828-830, 1985

[6] S.R.Cain, F.C.Burns, C.E.Otis, B.Braren: Photothermal description of polymer ablation: Absorption behavior and degradation times scale. J.Appl.Phys. 72(11):5172-5178, 1992

[7] S.Petzoltd, P.P.Elg, M.Reichling, J.Reif, E.Matthias: Surface laser damage thresholds determined by photoacoustic deflection, Appl.Phys.Lett. 53 (1988) 2005

[8] E.Matthias, M.Reichling, J.Siegel, O.W.Käding, S.Petzoldt, H.Skurk, B.Bizenberger, E.Neske: Appl.Phys.A, (1994), in press 